
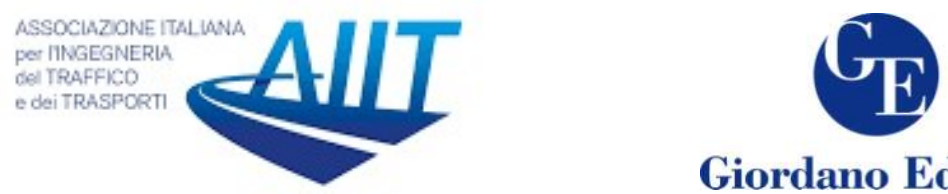

Giordano Editore

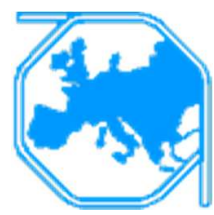

\title{
Modelling Behaviour of Shuttle Service Users and Preference towards a Proposed Bus Rapid Transit Line
}

\author{
Afzal Ahmed ${ }^{* *}$, Syeda Ofaq Raza Zaidi ${ }^{2}$, Mir Shabbar Ali $^{3}$, Palwasha Gul $^{4}$ \\ ${ }^{1}$ Assistant Professor, Department of Urban \& Infrastructure Engineering, NED University of Engineering \& \\ Technology, University Road, Karachi, Pakistan. \\ Email: afzalahmed@neduet.edu.pk
}

${ }^{2}$ Research Assistant - Exascale Open Data Analytics Lab, NED University of Engineering \& Technology, University Road, Karachi, Pakistan.

Email: ofaqalixaidi@gmail.com
${ }^{3}$ Dean Faculty of Civil and Petroleum Engineering, NED University of Engineering \& Technology, University Road, Karachi, Pakistan.
Email: deancpl@neduet.edu.pk

${ }^{4}$ Graduate Student, Transport Systems Engineering, Sapienza University of Rome, Rome, Italy

Email:palgu148@gmail.com

\begin{abstract}
This paper analyses the behaviour of university students in their mode selection and their preference towards a proposed bus rapid transit (BRT) line in Karachi, Pakistan. This BRT line, known as Red Line, has a major portion of its route along the University Road. Most of the major higher education institutions of Karachi are located along University Road. A preference survey was conducted from the students to determine individual preferences towards attributes of existing travel modes and the proposed BRT line. The respondents were classified into three categories which included users of private vehicles, public transport, and university shuttle service. The existing literature lacks in behaviour modelling of shuttle service users. This research models the behaviour of shuttle users and compares their behaviour with the commuters of other transport modes.

The influencing factors examined in this research included one-way travel time, travel fare, and level of comfort during the travel. The utility model developed in this research shows that students who use private vehicles value travel time more than the other attributes. On the contrary, the commuters of the shuttle service are more sensitive to travel fare. This research shows that the behaviour of shuttle users is significantly different than the other commuters. The multinomial logit (MNL) model was applied to estimate the number of trips expected to transfer to the proposed BRT line. Results show that the shuttle service users will be least influenced by the introduction of BRT, as the shuttle service offers subsidized fares with more convenience. The model developed in this paper can be used by the policymakers to make the BRT more attractive for students and the general public.
\end{abstract}

Keywords: Mode choice modelling; Multinomial logit model; Preference surveys; Travel mode service attribute; Karachi, Pakistan.

* Corresponding author: Afzal Ahmed (afzalahmed@neduet.edu.pk) 
European Transport $\backslash$ Trasporti Europei (2020) Issue 79, Paper nº 6, ISSN 1825-3997

\section{Introduction}

In the last few years, rapid population growth in developing and progressing cities has resulted in increased demand for transportation of goods and people. Due to the lack of adequate public transport system, many big cities in developing countries like Bangkok, Dhaka, and Karachi are facing traffic congestion problems (Noman et al., 2020, Khan et al., 2004). Karachi is one of the largest cities and major commercial hub of Pakistan, with a population of 14.9 million (Census, 2017). Despite being one of the megacities, Karachi lacks a proper mass transit (Noman et al., 2020). The existing informal public transport system is continuously deteriorating, which results in the shift of commuters to private vehicles. However, a specific group of commuters (usually low income with no finances to afford a private vehicle) still depends on public transport despite poor conditions and less availability of public transport. The unreliable and poorly operated public transport is resulting in an increase in vehicular traffic on roads of Karachi. The number of registered vehicles in Karachi has increased from 1.13 million in 2013 to 4 million in 2016 (Ahmed et al., 2019). Till 2016, the total number of registered cars in Karachi was 1.2 million, and the number of registered motorbikes was 2.3 million (Taslim, 2017).

As a result of a recent positive shift in the policymaking, various BRT lines have been planned, and some are in the construction phase in Karachi. However, there is a lack of data and data-driven models to depict the behaviour of commuters in their mode choice. Travel behaviour modelling is critical for demand analysis, where overall demand is the accretion of individuals' choices. For each journey, commuters have the choice between different travel modes and the decision is made by the commuters based on the mode-specific characteristics and suitability of the given mode for that journey (Gärling, 2005, Ajzen, 1991, Carver and Scheier, 2001). Choice models have been widely used in transportation and other fields to represent the selection of one alternative among several options (Wen and Koppelman, 2001, de Lapparent et al., 2013, Marcucci and Scaccia, 2004). Mode choice modelling is an essential element in the overall transport planning process which has been applied by policymakers and planners to test the proposed policy scenarios (Meyer and Miller, 1984, Balmer, 2007, Davidson et al., 2007, Pas, 1997, Vovsha et al., 2002).

Discrete choice modelling is one of the widely used techniques to analyze and predict travel choice of commuters by directly modelling individual preferences (Ben-Akiva and Lerman, 1985). Individual choice models are developed by the approach of utility maximization, which assumes that an individual chooses an alternative that appears to maximize the utility (Hatzopoulou and Miller, 2009). The art of selecting an appropriate choice model for a particular condition requires a strong understanding of the theoretical and methodological background of the model (Antonini et al., 2006, Bierlaire and Frejinger, 2008, Ben-Akiva and Boccara, 1995). Rizzi and de Dios Ortúzar (2003) concluded that by assuming an independent and identical distribution of decisions for mode choice through Gumbel distribution type I, a family of logit models can easily be estimated under the utility maximization framework.

The choice modelling techniques depend on the data acquired from the selected respondents. The survey is either a Revealed Preference (RP) survey or a Stated Preference (SP) survey. Bradley and Daly (1994) suggested a different approach by using RP data for estimating demand models and compared logit and probit model estimation techniques. SP data, collected by developing different hypothetical travel situations, have been used in situations where observed choice behaviour is not enough to model the context of interest. SP data can be used to find the type of 
travel alternates or characteristics which do not yet exist or qualitative attributes which can be very difficult to measure otherwise (Kocur et al., 1981, Sheldon and Steer, 1982, Lindhjem and Navrud, 2011, Abbe et al., 2007, Koppelman and Bhat, 2006, Rudel, 2004). Hensher and Bradley (1993) integrated the use of RP and SP data and proposed that their integration enhances the explanatory power of RP data. Polydoropoulou and Ben-Akiva (2001) combined SP and RP data for application in the Nested Logit Model.

The existing literature contains extensive studies on mode choice behaviour of commuters. Khan (2007) developed a mathematical model, capable of modelling and forecasting travel behaviour on the multimodal environment of Redland Shire in Australia. This model can also be used to test the elasticity of different attributes under a proposed virtual environment. Bhat (1995) developed a heteroscedastic value model for intercity mode choices in the Toronto-Montreal corridor. The developed model overcomes the self-reliance of irrelevant alternatives and allows flexible cross elasticity among alternatives as compared to the nested logit model. Fujii and Gärling (2003) improved the accuracy of stated preference methods in travel demand modelling by applying attitude theory. The results of the surveys were consistent with their predictions by which the study was able to do travel demand forecasting in Japan. Ahern and Tapley (2008) revealed the perceptions of the passengers for the Eight Interurban Rail and Bus in Dublin, Ireland. The study suggested that respondents chose the modes predominantly on time and cost associated with travelling and gave less importance to frequency and reliability. Baidoo and Nyarko (2015) performed an econometric analysis of commuters regarding their choice of different modes of transportation in Ghana. User preferences were collected either by SP or RP, and binary logit models were developed to capture commuter's preferences. The results from the binary choice model show that the commuters ought to choose public transport as the price is relatively less, and using public transport has become their habit. Asensio (2002) analyzed the travel mode choices for suburbanized commuters in Barcelona, Spain, using a nested logit model. Arasan et al. (1998) studied the mode choice behaviour of travellers using motorized vehicles in India. The multinomial logit approach was used for the development of mode choice models for travellers stratified based on vehicle availability. This study also included random socio-economic factors that affect utilities and mode selection. Chari and Khanna (1978) applied a binary logit model to study the mode choice behaviour of commuters in India for work-related trips. Rao (1993) also studied the behaviour of commuters for work-related trips in India by developing sequential binary choice models for work trips.

Among various classes of road users, students are a significantly different road user group with unique characteristics. The behaviour of students towards mode choice has been studied exclusively. Mohammed and Shakir (2013) examined the factors that affect the mode choice preference of students in the National University Malaysia. The logit model was applied for the analysis of mode choice behaviour and to find the shifting of private vehicle users to public transport. Results indicated that by reducing the travel time of public transport by $70 \%$, the number of private car users could be reduced by $84 \%$ while reduction of travel cost would also increase the public transport users. De Guzman et al. (2005) analyzed the mode choice of students in the selected schools in Metro Manila, Philippines and studied the travel patterns of students. Zhang et al. (2017) studied the travel mode choice behaviour of school trips for students of age 7-18 years in Beijing, China. Whalen et al. (2013) examined the mode choice behaviour of university students in Hamilton, Canada and concluded that the university students tend to use active transport modes 
more than other commuters. Various other studies have examined different aspects of mode choice behaviour of students (Müller et al., 2008, Ewing et al., 2004, Klöckner and Friedrichsmeier, 2011).

The above-cited literature shows that a significant amount of research has been published in the literature related to mode choice modelling and commuter preferences towards public transit. Although various researchers have studied the behaviour of students in mode choice, the research on modelling behaviour of shuttle users lacks in the existing literature. This paper aims to address this gap by modelling the behaviour of university students towards mode selection, including shuttle service, private and public transport modes.

In Pakistan, public sector universities provide shuttle service to their students on a significantly subsidized fare, which makes shuttle service a primarily different mode of transport with distinct attributes. Shuttle service operates on a fixed route and schedule with limited frequency for authorized persons only. A significant number of students prefer to commute by shuttle service due to its low fares and convenience. This study for the first time models the behaviour of shuttle users along with commuters from private and public transport modes. The preference of students towards a proposed BRT line which passes through University Road is also modelled, and the behaviour of students with different transportation modes is compared. The proposed mode choice preference models could be useful for policymakers to improve the specific service attributes, which can make the BRT lines more attractive for students and other commuters in Karachi. This study may be used as a reference framework for evaluating commuters' behaviour in other cities and projects in Pakistan.

\section{Survey Design and Data Collection}

Mode choice behaviour modelling requires characteristic mode preference data. For this purpose, a questionnaire was designed to collect the relevant data. The survey questionnaire was composed of three main sections. The first section collected information related to socio-economic and demographic information of respondents. The second section was intended to collect individual travel behaviour, current mode choice, and travel characteristics. The third section was based on stated choice questions, where a series of binary choice questions related to proposed BRT were included. The attributes related to travel modes were selected based on available literature (Nkurunziza et al., 2012). Travel mode attributes included in this study were travel time, travel cost, safety and comfort level. A pilot survey was conducted before the main survey at one of the selected universities to check the efficiency and response rate of the designed questionnaire. After a reasonable response rate from the pilot survey, the designed questionnaire was selected for the main survey.

The sample size was estimated by the method of stratified random sampling with each stratum representing a university located along the BRT route. Figure 1 shows the location of selected universities. The random sampling technique was employed for surveying students in each stratum. Based on a $95 \%$ confidence level, the overall sample size was estimated to be 873 students for a total student population of 42,794 at the selected universities with a margin of error of \pm $3.3 \%$. Table 1 shows the number of enrolled students and the estimated sample size for each university. Respondents (students) were approached randomly for personal interviews at their respective universities during breaks and short intervals to achieve a high response rate.

The preference of students towards all three main transportation modes to commute to universities was examined. The transportation modes were classified into private vehicles, public transport, and the shuttle service. 


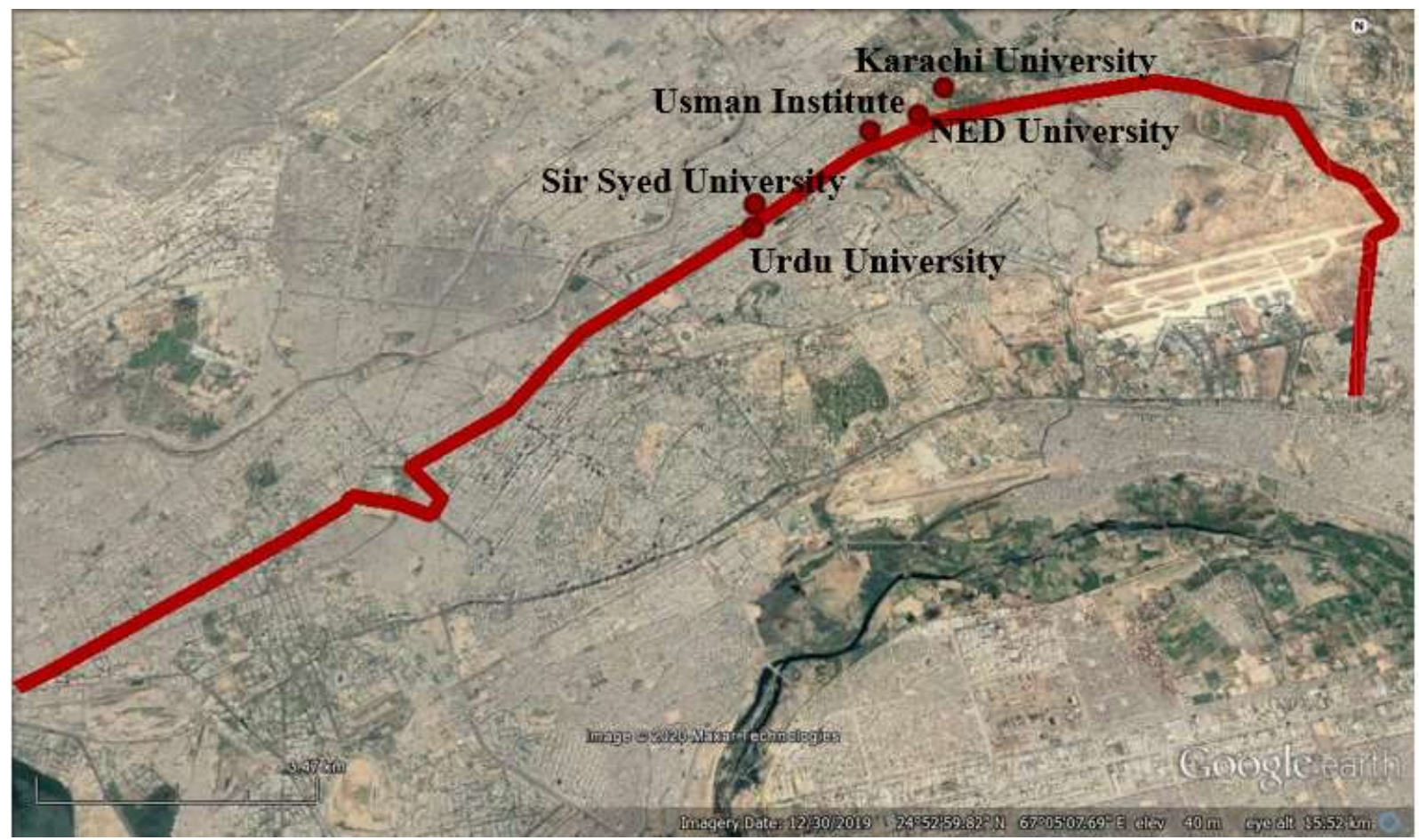

Figure 1: Universities along the proposed BRT Red Line route

Table 1: Population and sample size of selected universities.

\begin{tabular}{|l|l|l|l|}
\hline Institute & Student Population & $\begin{array}{l}\text { Individuals' } \\
\text { Surveyed }\end{array}$ & Survey Date \\
\hline $\begin{array}{l}\text { Usman Institute of } \\
\text { Technology. }\end{array}$ & 1,700 & 38 & May 9, 2018 \\
\hline $\begin{array}{l}\text { Sir Syed University } \\
\text { of Engineering and } \\
\text { Technology. }\end{array}$ & 3,800 & 79 & May $10^{\text {th }}, 2018$ \\
\hline $\begin{array}{l}\text { Federal Urdu } \\
\text { University. }\end{array}$ & 7,800 & 156 & May $14^{\text {th }}, 2018$ \\
\hline Karachi University. & 21,494 & 437 & May $15^{\text {th }}-18^{\text {th }}, 2018$ \\
\hline $\begin{array}{l}\text { NED University of } \\
\text { Engineering and } \\
\text { Technology. }\end{array}$ & 8,000 & 163 & May $22^{\text {nd }}-23^{\text {rd }}, 2018$ \\
\hline Total & 42,794 & 873 & \\
\hline
\end{tabular}


European Transport $\backslash$ Trasporti Europei (2020) Issue 79, Paper nº 6, ISSN 1825-3997

\section{Stated Choice Design}

The SP technique is widely used in transportation planning due to its potential to measure commuters' response towards hypothetical scenarios and planned changes in the transportation network. SP survey questions were designed to record the preference of commuters toward various alternatives after the introduction of BRT Red Line. Each scenario is a combination of different levels of attributes. The respondents were asked to select the alternative, which they think is most appealing according to their preferences. Six different scenarios were presented to the respondents. Figure 2 shows one of the six scenarios presented to the respondents.

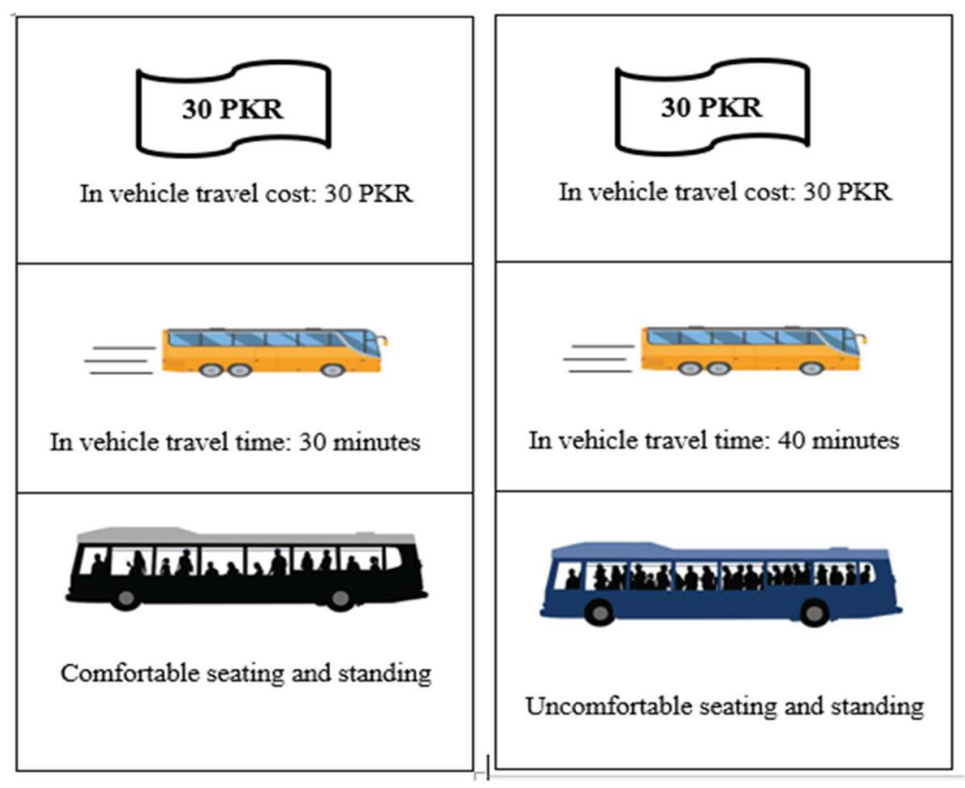

Figure 2: Scenario 1 of 6 of stated choice questions

\section{Statistical Data Analysis}

Statistical and descriptive analysis was performed for the data collected through the preference survey. Figure 3 shows the attitude of public transport users towards different attributes. Most of the public transport users consider safety as the most important attribute. Further analysis of public transport users revealed that a significant proportion (68\%) of surveyed public transport commuters were female who does not have access to private vehicles and cannot ride motorbikes like male commuters due to prevailing social norms. The public transport is considered as the safest mode of transport. Therefore, students who use public transport assign more weight to safety. Figure 4 shows the responses of private vehicle users, and it reveals that private vehicle users consider time as the most important attribute. The use of a private vehicle is associated with less travel time in comparison with public transport, as the public transport takes longer time due to low frequency, poor accessibility, and slow operating speeds. Similarly, shuttle users were asked for their response towards different attributes and results show that shuttle users consider time and safety as the most important attributes. Figure 5 shows the response of shuttle commuters. Shuttle service is also a safer mode of transport like public transport and is considered as significantly faster than public transport. However, it is operated by the universities on a limited schedule and is one of the least flexible options available to students. 
European Transport $\backslash$ Trasporti Europei (2020) Issue 79, Paper nº 6, ISSN 1825-3997

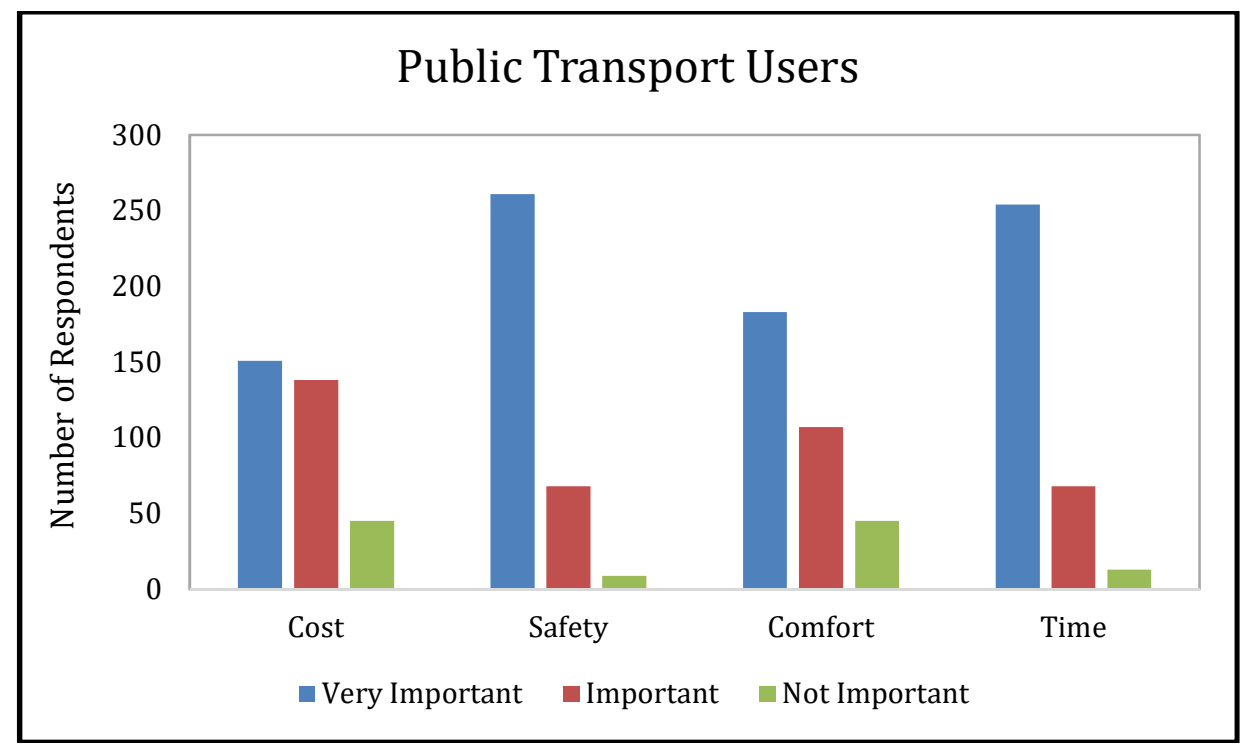

Figure 3: Response of public transport users towards different travel mode choice attributes.

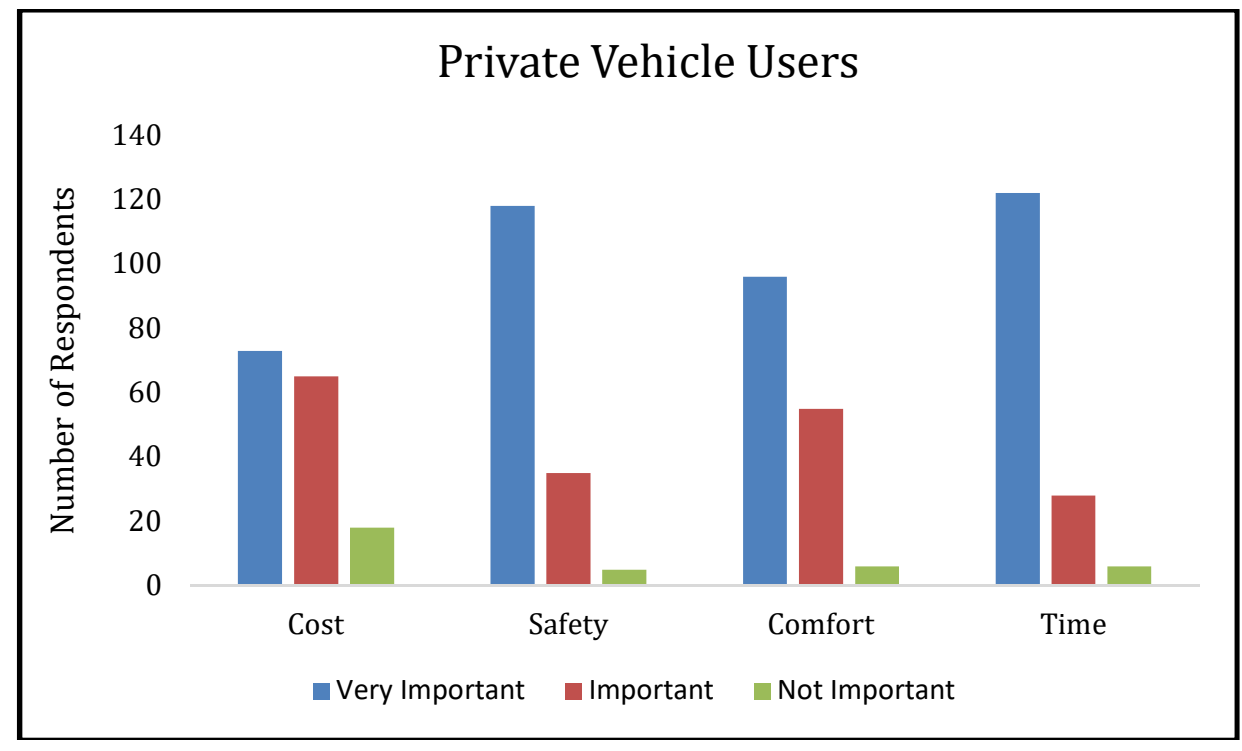

Figure 4: Response of private vehicle users towards different travel mode choice attributes. 


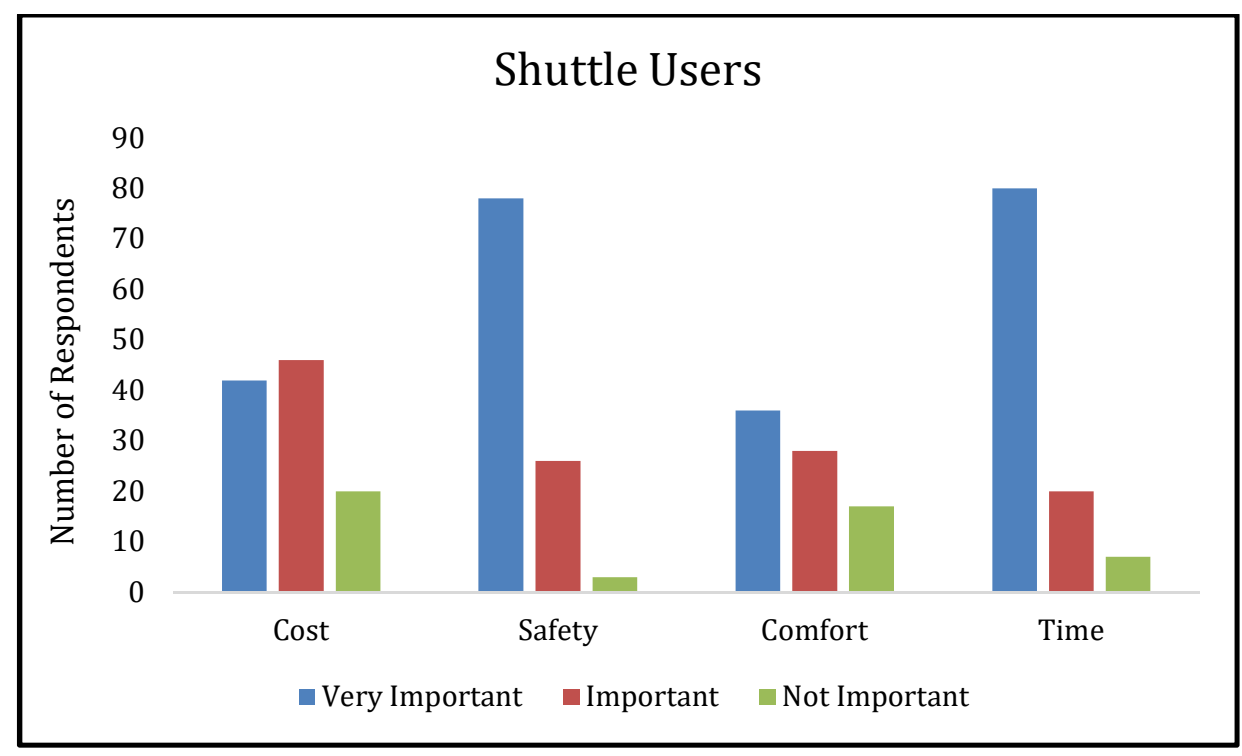

Figure 5: Response of shuttle service users towards different travel mode choice attributes.

\subsection{Model structure and explanatory variables}

The data collected from the preference survey was analyzed using a utility model. The utility model assumes that a decision-maker (commuter) faces a utility maximization problem based on cost and quality of service stemming from using a given mode and uncertainty of choosing the given mode. For this research, a random utility model known as multinomial logit (MNL) is used to model commuter preferences. Variables are estimated by the maximum likelihood method using SPSS analytical system. A random utility model is expressed as follows:

$$
U_{\mathrm{n}}=V_{n}+\epsilon_{n}
$$

Where $U_{\mathrm{n}}$ is the utility of particular mode $n, V_{n}$ is the systematic utility of that mode, and $\epsilon_{n}$ is the error in measuring the utility. The systematic utility $V_{n}$ depends upon the attributes of travel mode considered in the modelling process, which can be given as:

$$
V_{n}=\beta_{1} X_{n 1}+\beta_{2} X_{n 2}+\beta_{3} X_{n 3}+\ldots \ldots \ldots+\beta_{k} X_{n k}
$$

Where $\beta_{1} X_{n 1}, \ldots \ldots, \beta_{k} X_{n k}$ are $k$ number of attributes for mode $n$ and $\beta_{1}, \ldots \ldots \ldots, \beta_{k}$ are weights associated with each attribute. The systematic utility function for modes of transport considered in this research are given below:

$$
\mathrm{V}_{\mathrm{BRT}}=\beta_{\mathrm{T}} \mathrm{T}_{\mathrm{BRT}}+\beta_{\mathrm{F}} \mathrm{F}_{\mathrm{BRT}}+\beta_{\mathrm{C}} \mathrm{C}_{\mathrm{BRT}}
$$

Where $\mathrm{V}_{\mathrm{BRT}}$ is the net utility function for BRT, $\mathrm{T}_{\mathrm{BRT}}$ is the total travel time of BRT (one way), $\mathrm{F}_{\mathrm{BRT}}$ is total travel fare of BRT (one way) and $\mathrm{C}_{\mathrm{BRT}}$ is level of comfort attained while traveling in $\mathrm{BRT}, \beta_{\mathrm{T}}$ is the coefficient associated with travel time, $\beta_{\mathrm{F}}$ is the coefficient associated with fare and $\beta_{\mathrm{C}}$ is the coefficient associated with travel comfort. Similarly, utilities for all other modes are stated as;

$$
\begin{gathered}
\mathrm{V}_{\mathrm{PVT}}=\beta_{\mathrm{T}} \mathrm{T}_{\mathrm{PVT}}+\beta_{\mathrm{F}} \mathrm{F}_{\mathrm{PVT}}+\beta_{\mathrm{C}} \mathrm{C}_{\mathrm{PVT}} \\
\mathrm{V}_{\mathrm{PT}}=\beta_{\mathrm{T}} \mathrm{T}_{\mathrm{PT}}+\beta_{\mathrm{F}} \mathrm{F}_{\mathrm{PT}}+\beta_{\mathrm{C}} \mathrm{C}_{\mathrm{PT}}
\end{gathered}
$$


European Transport $\backslash$ Trasporti Europei (2020) Issue 79, Paper nº 6, ISSN 1825-3997

$$
\mathrm{V}_{\mathrm{S}}=\beta_{\mathrm{T}} \mathrm{T}_{\mathrm{S}}+\beta_{\mathrm{F}} \mathrm{F}_{\mathrm{S}}+\beta_{\mathrm{C}} \mathrm{C}_{\mathrm{S}}
$$

Where $\mathrm{V}_{\mathrm{PVT}}, \mathrm{V}_{\mathrm{PT}}, \mathrm{V}_{\mathrm{S}}$ are net utility functions for private vehicles, public transport, and shuttle service, respectively.

\subsection{Model outputs}

The data collected from randomly selected students of universities were analyzed using linear regression to estimate the coefficients of the utility equations. The values of coefficients from regression analysis are shown in table 2 . The regression analysis shows that the selected parameters for mode choice modelling, which include travel time, travel cost, and comfort are significant as the p-value for these parameters is less than 0.05 . The coefficients of travel time and travel cost for all the modes are negative, which indicates that the mode choice is sensitive to these factors, and an increase in the value decreases the utility of the mode. The comparison of coefficients of out-of-pocket cost for the existing three modes of transport shows that the coefficient is highest for the users of shuttle service (-0.325). This shows that the students who select shuttle service for commuting are more sensitive to out-of-pocket cost due to which they choose shuttle service, which offers subsidized fares.

On the contrary, the coefficient of out-of-pocket cost for commuters of private vehicles is the least $(-0.0053)$, which shows that there is a significant difference between the coefficients of shuttle service users and commuters of private vehicles. The coefficient of out-of-pocket cost for the commuters of public transport lies between shuttle service and private vehicles. The comparison as mentioned earlier shows that the users of shuttle service are significantly different from the users of other conventional modes, as the shuttle service provides a fast, reliable, and comfortable ride to the students. The regression analysis also reveals that the coefficients of travel time and comfort are also higher for shuttle users due to the factors mentioned earlier. However, limited accessibility and less time flexibility in comparison with other modes are some of the drawbacks of a shuttle service.

The utility models presented in table 2 are used to evaluate the preference of commuters from all the existing modes towards the proposed Red Line BRT.

Table 2: Coefficients of the utility model for different transport modes

\begin{tabular}{|l|c|c|c|c|}
\hline Travel Mode & Attributes & Coefficients & t-ratio & p-value \\
\hline \multirow{4}{*}{ Private vehicle } & Travel Time & -0.0237 & -6.9 & 0.000 \\
\cline { 2 - 5 } & Travel Fare & -0.0053 & -2.0 & 0.000 \\
\cline { 2 - 5 } & Comfort & 0.1060 & -3.4 & 0.015 \\
\cline { 2 - 5 } & Constant & -2.4812 & -12.3 & 0.010 \\
\hline \multirow{3}{*}{$\begin{array}{l}\text { Public } \\
\text { Transport }\end{array}$} & Travel Time & -0.043 & 6.5 & 0.010 \\
\cline { 2 - 5 } & Travel Fare & -0.016 & 10.5 & 0.005 \\
\cline { 2 - 5 } & Comfort & 0.326 & -8.8 & 0.006 \\
\cline { 2 - 5 } & Constant & -1.964 & -3.9 & 0.001 \\
\hline \multirow{4}{*}{ Shuttle } & Travel Time & -0.074 & 6.5 & 0.005 \\
\cline { 2 - 5 } & Travel Fare & -0.325 & 8.5 & 0.000 \\
\cline { 2 - 5 } & Comfort & 0.463 & -5.0 & 0.001 \\
\cline { 2 - 5 } & Constant & 0.954 & -2.9 & 0.004 \\
\hline
\end{tabular}


European Transport $\backslash$ Trasporti Europei (2020) Issue 79, Paper nº 6, ISSN 1825-3997

\begin{tabular}{|c|c|c|c|c|}
\hline \multirow{3}{*}{ BRT } & Travel Time & -0.432 & 6.5 & 0.001 \\
\cline { 2 - 5 } & Travel Fare & -0.002 & 8.5 & 0.005 \\
\cline { 2 - 5 } & Comfort & 0.563 & -5.0 & 0.000 \\
\cline { 2 - 5 } & Constant & 1.865 & -2.9 & 0.002 \\
\hline
\end{tabular}

\subsection{The sigmoid of multinomial logit probabilities}

The sigmoid of MNL probabilities of BRT is illustrated in Figure 6 . The probability of choosing BRT is shown as a function of its utility by keeping the utilities of other alternatives constant. The $\mathrm{S}$ shape shows that the probability range varies between 0 and 0.87 . The probability of choosing BRT increases with an increase in the utility of BRT in comparison with other transport modes. The figure further shows that the function has a very gradual slope at extreme values of BRT utility and is much steeper in the middle region of the probability curve. This implies that when the representative utility of BRT is very low or very high, compared to other available alternates, a small increase in utility of BRT due to change in its attributes will not substantially affect its choice probability. The curve shown in figure 6 can be used to achieve the desired shift of commuters to the proposed BRT by increasing the utility either by keeping low fares or reducing travel times.

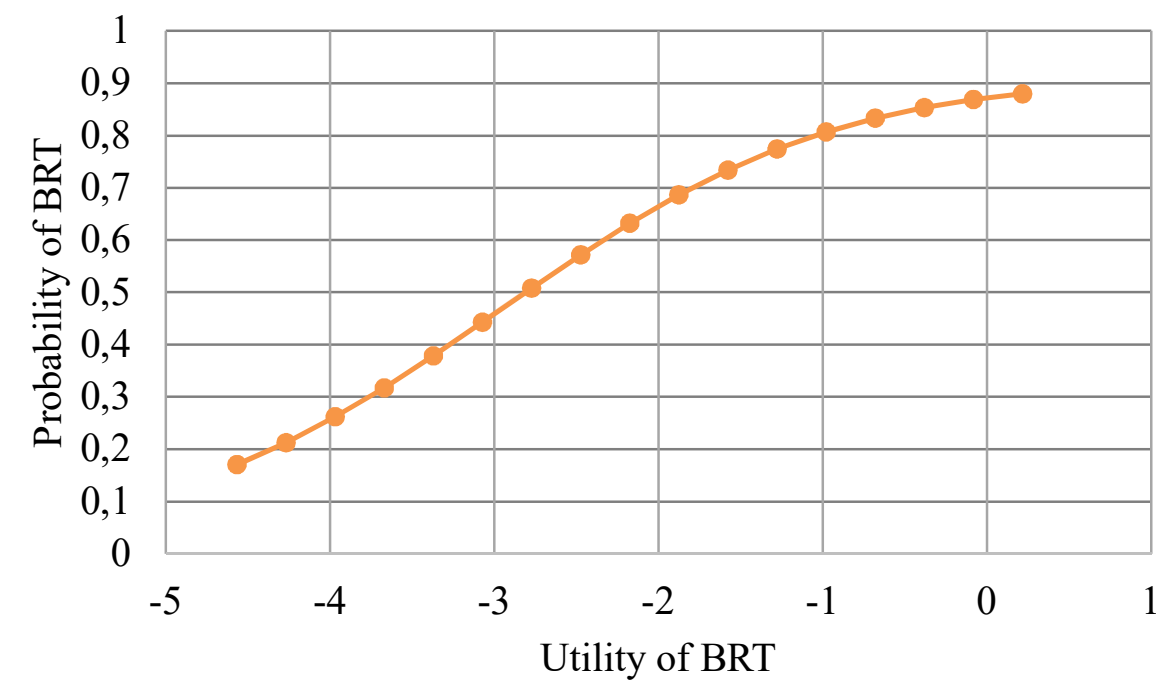

Figure 6: Effect on the probability of choosing BRT by variation in utility

\subsection{Variation of BRT demand with travel time and travel fare}

The developed utility models show that BRT commuters are sensitive towards travel fare and travel time. The demand for the proposed BRT Red Line will be highly dependent on these two attributes of the service. Utilities were calculated to study the effect of different values of travel time and travel fare on BRT demand. These utilities were calculated for the average distance, based on the data collected from the students. The value of average distance was calculated as $12 \mathrm{~km}$.

To study the effect of travel time, the fare was kept constant, and utilities were calculated for different values of travel times, ranging from 15 to 45 minutes for the average commute distance of $12-\mathrm{km}$ (corresponding to the average speed of $16 \mathrm{~km} / \mathrm{hr}$ to $48 \mathrm{~km} / \mathrm{hr}$ ). Similarly, to study variation in demand with a change in travel fare, travel time was kept constant, and utilities were estimated for travel fare ranging from 30 Rs for a journey (expected fare of proposed BRT Red 
Line) to 115 Rs per journey. Travel time and travel fare for private vehicles and public transport were kept constant. The average observed values for travel time and travel fare were used for all scenarios. The derived utilities were then used to estimate the proportion of student population choosing BRT for their commute.

Figure 7 shows the variation in demand with travel time for BRT commuters. It shows that commuters value their travel time substantially. There is a significant decrease in BRT users with an increase in travel time. Therefore, authorities should consider keeping the travel time of BRT as low as possible to make it more attractive for users.

The change in demand with travel fare is shown in figure 8. Demand in figure 8 was calculated by keeping the travel time constant so that the effect of travel fare can be evaluated. The demand versus travel fare curve shows that a significant number of commuters will use BRT despite an increase in fare from 30 Rs to 120 Rs. This shows that commuters are comparatively less sensitive to the change in travel fare of BRT, and it would be the preferred mode of transport for the students. The comparison of figure 7 and figure 8 shows that travel time is more valued by the commuters in comparison with travel fare. This may be attributed to the fact that respondents (students) belong to a specific group of commuters, and the behaviour of other commuter groups could be different. Most of the students at higher education institutions belong to families with a comparatively better financial background, resulting in their sensitive behaviour towards travel time and an insensitive approach towards travel fare.

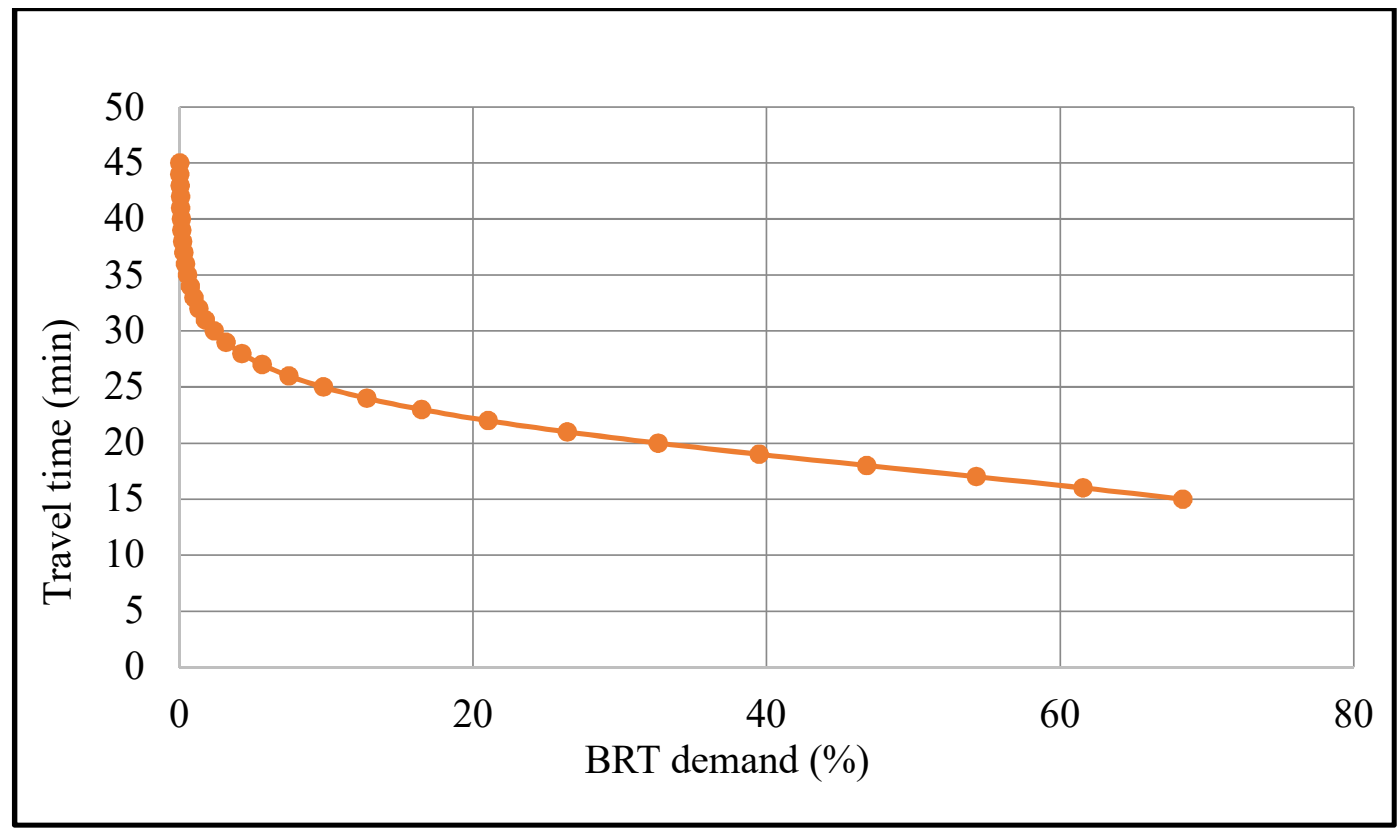

Figure 7: The effect of travel time on students' attitude towards BRT selection. 


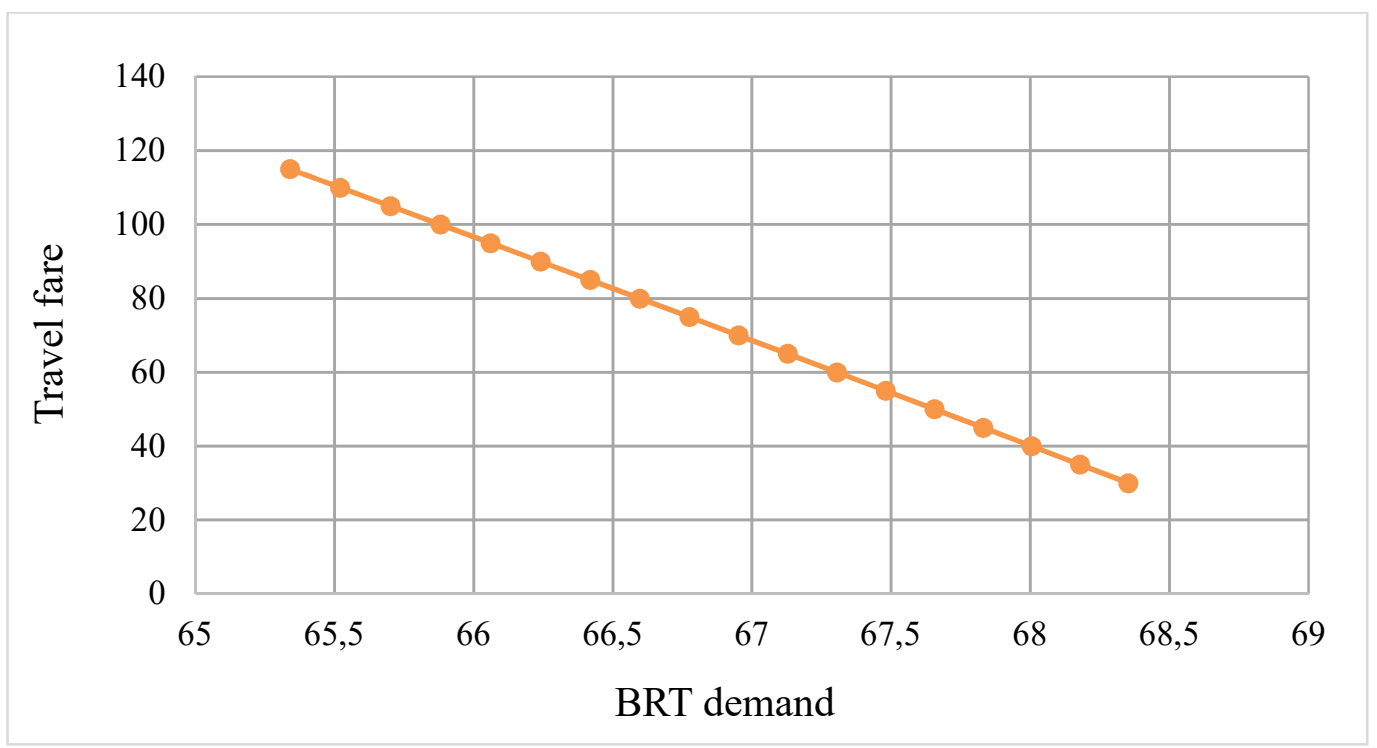

Figure 8: Travellers' attitude towards BRT travel fare.

\subsection{The behaviour of shuttle users}

The utilities for the shuttle and other transport modes derived earlier were used to analyze shuttle commuters' behaviour. Since shuttle service is a subsidized mode of transportation provided by respective universities to their students, the preference of shuttle commuters towards choice attributes is different from all other modes of transportation. Utility coefficients for shuttle commuters show that shuttle users are highly sensitive towards choice attributes, including travel time and fare, as compared to private vehicles and public transport users.

The proportion of students who use public transport, private vehicles, and shuttle service before and after the introduction of the BRT Red Line is shown in Table 3. The proportions of commuters at present (before Red Line) are based on the survey data collected from randomly selected students, whereas the proportions after BRT are estimated at the expected fare of PKR 30 and average travel speed of $30 \mathrm{~km} / \mathrm{hr}$. Results from table 3 show that around $5.2 \%$ of existing shuttle commuters will shift to Red Line after its introduction. This indicates that the shuttle users are least influenced by BRT introduction. The main reason for shuttle commuters not shifting towards BRT is the lesser fare of shuttle service and low travel times in comparison with the proposed BRT.

Table 3: Predicted Market share of studied modes before and after the introduction of BRT Red Line

\begin{tabular}{|c|c|c|}
\hline Mode of Commute & $\begin{array}{c}\text { Proportion before BRT Red } \\
\text { Line }\end{array}$ & $\begin{array}{c}\text { Proportion after BRT Red } \\
\text { Line }\end{array}$ \\
\hline Public transport & $31.07 \%$ & $25.05 \%$ \\
\hline Private vehicles & $42.3 \%$ & $34.15 \%$ \\
\hline Shuttle & $26.6 \%$ & $21.4 \%$ \\
\hline BRT Red Line & - & $19.31 \%$ \\
\hline
\end{tabular}




\section{Results and Discussions}

The multinomial logit model for mode choice analysis of educational trips was developed in this research. Table 3 shows that private vehicles are the most preferred mode of transport of the students at the selected universities due to comfortable ride and lesser travel time as compared to public transport and shuttle service. The commuters who commute using public transport have no access to private vehicles, which makes them use public transport for commute, although they prefer comfortable ride with lesser travel time. It implies that policymakers for BRT can attract a large number of public transport users by providing quality service with lesser travel time and a higher level of comfort during the travel.

The utilities derived in this research are significantly different when compared with the utilities reported in the literature for developed countries and commuters from the general public. Table 4 compares the utility coefficients estimated in this research with the utilities reported in the literature. Table 4 also shows that none of the reported studies has considered shuttle users as a different group of commuters.

Studies listed in table 4 show that the mode choice behaviour of commuters varies in different study areas, which depends on the socio-economic background of commuters and performance of the available alternates. Arasan et al. (1998) studied the mode choice for work trips of commuters in an Indian city who commute using their personal vehicle. The study concluded that the commuters give significantly higher consideration to the out-of-pocket cost in comparison with travel time. Ahern and Tapley (2008) shared a similar finding for the bus commuters in Dublin, Irelan. On the contrary, the commuters in Redland Shire, Australia gave more weight to travel time in comparison with the out-of-pocket cost. Tushara et al. (2013) studied the behaviour of commuters for work trips in Calicut, India. The mode choice model developed in the study revealed that car drivers prefer less travel time over travel cost. Whereas, the commuters who use bus give more importance to the travel fare in comparison with travel time.

Similarly, this study also shows that students with different mode preference have a different attitude towards the attributes of the transport mode. The students who travel to the university using a private vehicle value their travel time more than the out-of-pocket cost. Whereas, the opposite attitude of shuttle users is reflected by the mode choice model developed in this study.

Table 4: Comparison of utility coefficients with other studies

\begin{tabular}{|c|c|c|c|c|c|c|c|c|c|c|c|}
\hline 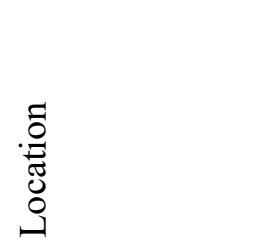 & 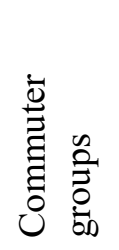 & 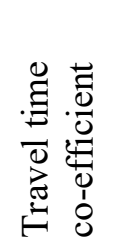 & 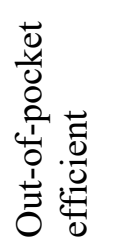 & 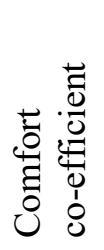 & 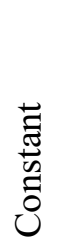 & 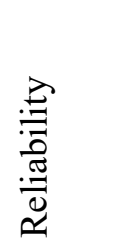 & 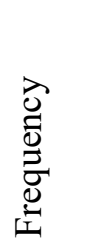 & 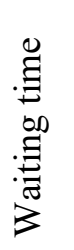 & 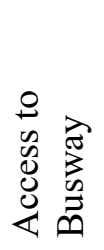 & $\begin{array}{l}\mathscr{\Xi} \\
\stackrel{0}{\Xi} \\
\stackrel{\Xi}{E}\end{array}$ & $\sum_{\pi}^{\infty}$ \\
\hline $\begin{array}{l}\text { Dar-es-salaam, } \\
\text { Tanzania } \\
\text { (Nkurunziza } \\
\text { et al., 2012) }\end{array}$ & BRT & -0.034 & -0.006 & 1.81 & - & - & - & - & - & - & . \\
\hline $\begin{array}{l}\text { Tiruchirappalli } \\
\text { city, India } \\
\text { (Arasan et al., } \\
\text { 1998) }\end{array}$ & Car & -0.487 & -2.993 & - & - & - & - & - & - & - & 7 \\
\hline $\begin{array}{l}\text { Dublin, Ireland } \\
\text { (Ahern and } \\
\text { Tapley, 2008) }\end{array}$ & Bus & $\begin{array}{c}- \\
0.0145\end{array}$ & -0.141 & - & - & -0.007 & 0.006 & - & - & - & 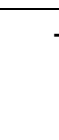 \\
\hline
\end{tabular}




\begin{tabular}{|c|c|c|c|c|c|c|c|c|c|c|c|}
\hline $\begin{array}{l}\text { Toronto, } \\
\text { Montreal } \\
\text { (Bhat, 1995) }\end{array}$ & Car & $\begin{array}{c}- \\
0.0105\end{array}$ & -0.042 & - & - & - & 0.084 & - & - & - & - \\
\hline \multirow{2}{*}{$\begin{array}{l}\text { Redland Shire, } \\
\text { Australia } \\
\text { (Khan, 2007) }\end{array}$} & Car & -0.065 & -0.004 & - & -1.550 & - & - & - & - & & \\
\hline & Bus & -0.048 & -0.003 & - & - & - & - & -0.052 & -0.046 & - & - \\
\hline \multirow{2}{*}{$\begin{array}{l}\text { Calicut, India } \\
\text { (Tushara et } \\
\text { al., 2013) }\end{array}$} & Car & -0.211 & -0.166 & - & -5.213 & - & - & 0.193 & - & 2.689 & 2.131 \\
\hline & Bus & -0.319 & -0.438 & - & -0.512 & - & - & 0.244 & - & - & - \\
\hline $\begin{array}{l}\text { Toronto, } \\
\text { Canada (Miller } \\
\text { et al., 2005) }\end{array}$ & Transit & -0.210 & -0.215 & - & -4.434 & - & & - & - & - & - \\
\hline \multirow{4}{*}{$\begin{array}{l}\text { Karachi, } \\
\text { Pakistan } \\
\text { (This } \\
\text { Research) }\end{array}$} & \begin{tabular}{|l|} 
Private \\
Vehicle \\
\end{tabular} & $\begin{array}{c}- \\
0.0237 \\
\end{array}$ & $\begin{array}{c}- \\
0.0053 \\
\end{array}$ & 0.106 & -2.481 & - & - & - & - & - & - \\
\hline & \begin{tabular}{|c|} 
Public \\
transport
\end{tabular} & -0.043 & -0.016 & 0.326 & -1.964 & - & - & - & - & - & - \\
\hline & Shuttle & -0.074 & -0.325 & 0.463 & 0.954 & - & - & - & - & - & - \\
\hline & BRT & -0.432 & -0.002 & 0.563 & 1.865 & - & - & - & - & - & - \\
\hline
\end{tabular}

\section{Conclusions and Recommendations}

This research modelled the behaviour of university students selected from five major universities in Karachi. The existing literature in mode choice modelling contains several studies on modelling study trips of students from various levels, which shows that the students are classified as an independent road user group. Students are modelled as a separate road user group due to their intrinsically different characteristics, including age, socio-economic background, and trip characteristics. This study contributes to the existing body of knowledge by separately modelling the behaviour of shuttle service users. The study shows that the mode choice behaviour of students who use shuttle service is significantly different from other groups of students.

The behaviour of students in mode choice and their preference towards mode attributes was modelled. 873 students from the selected universities were interviewed, and the data was collected using a questionnaire-based survey. The students' preferences towards the attribute of their mode of travel, including private vehicle, public transport, and shuttle service, were recorded. The stated preference survey technique was used to investigate the modal shift of students towards a proposed BRT line that connects these universities with other areas of the city. The utility models were developed for the selected modes using multiple linear regression analysis.

The utility models show that the behaviour of shuttle service users is significantly different from the students who commute using public transport or private vehicles. This research shows that among the three modes of transport, the shuttle service users give the highest weight to travel fare or out-of-pocket cost. Whereas, the commuters of private vehicles regard travel time as the most significant attribute. Students who use public transport for their study trip consider comfort and safety as the most important attribute. The significant difference in the behaviour of students who use different transport modes shows that all the commuter groups should be studied in detail while modelling their 
preference towards a proposed change in transport network such as the introduction of a new BRT line. The outcome of MNL shows that about $19.3 \%$ of the students will change their existing mode and shift to the proposed BRT Red Line. The least proportion of shuttle users is expected to shift to the proposed BRT, whereas the highest proportion of commuters of private vehicles will change their current mode. Shuttle commuters will be least influenced by the introduction of BRT as they already travel on a mode which is faster and offers a subsidized fare.

The student population of the selected universities is around 42,794. Most of these students travel in the morning to attend classes and leave universities in the afternoon. Therefore, study trips make a significant proportion of the total trips along the proposed route of the BRT Red Line. The developed utility model shows that the travel time and comfort level can influence the mode choice of students. Therefore, the proposed BRT should be designed to provide a faster and comfortable journey. Furthermore, an optimal fleet size of buses would also ensure less time headway and a smaller value of persons per seat, thus making a journey more comfortable for the passengers.

The research shows that the commuters of different modes behave differently and detailed analysis of each road user group is essential in attaining an accurate behaviour model, which is critical in design and operation of new transportation facilities, including public transport.

\section{References}

ABBE, E., BIERLAIRE, M. \& TOLEDO, T. 2007. Normalization and correlation of cross-nested logit models. Transportation Research Part B: Methodological, 41, 795-808.

AHERN, A. A. \& TAPLEY, N. 2008. The use of stated preference techniques to model modal choices on interurban trips in Ireland. Transportation Research Part A: Policy and Practice, 42, 15-27.

AHMED, A., MEHDI, M. R., NGODUY, D. \& ABBAS, M. 2019. Evaluation of accuracy of advanced traveler information and commuter behavior in a developing country. Travel Behaviour and Society, 15, 63-73.

AJZEN, I. 1991. The theory of planned behavior. Organizational behavior and human decision processes, 50, 179-211.

ANTONINI, G., BIERLAIRE, M. \& WEBER, M. 2006. Discrete choice models of pedestrian walking behavior. Transportation Research Part B: Methodological, 40, 667-687.

ARASAN, V. T., RENGARAJU, V. \& RAO, K. K. 1998. Mode choice for work journeys of urban travellers owning motorized vehicles in India. Transportation planning and technology, $22,27-45$.

ASENSIO, J. 2002. Transport mode choice by commuters to Barcelona's CBD. Urban Studies, 39, 1881-1895.

BAIDOO, I. K. \& NYARKO, E. 2015. Stated preference modeling for a preferred transportation mode. Methodology, 5.

BALMER, M. 2007. Travel demand modeling for multi-agent transport simulations: Algorithms and systems. ETH Zurich.

BEN-AKIVA, M. \& BOCCARA, B. 1995. Discrete choice models with latent choice sets. International journal of Research in Marketing, 12, 9-24.

BEN-AKIVA, M. E. \& LERMAN, S. R. 1985. Discrete choice analysis: theory and application to travel demand, MIT press.

BHAT, C. R. 1995. A heteroscedastic extreme value model of intercity travel mode choice. Transportation Research Part B: Methodological, 29, 471-483.

BIERLAIRE, M. \& FREJINGER, E. 2008. Route choice modeling with network-free data. Transportation Research Part C: Emerging Technologies, 16, 187-198. 
BRADLEY, M. \& DALY, A. 1994. Use of the logit scaling approach to test for rank-order and fatigue effects in stated preference data. Transportation, 21, 167-184.

CARVER, C. S. \& SCHEIER, M. F. 2001. On the self-regulation of behavior, Cambridge University Press.

CENSUS. 2017. Provisional summary results of 6th population and housing census-2017 [Online]. pakistan: pakistan bureau of statistics. Available: http://www.pbs.gov.pk/content/provisional-summary-results-6th-population-and-housingcensus-2017-0 [Accessed -].

CHARI, S. R. \& KHANNA, S. K. 1978. Study of work trip travel in India. Transportation Engineering Journal of ASCE, 104, 89-105.

DAVIDSON, W., DONNELLY, R., VOVSHA, P., FREEDMAN, J., RUEGG, S., HICKS, J., CASTIGLIONE, J. \& PICADO, R. 2007. Synthesis of first practices and operational research approaches in activity-based travel demand modeling. Transportation Research Part A: Policy and Practice, 41, 464-488.

DE GUZMAN, M. P., DIAZ, C. E. \& BAGUIO CITY, P. D. Analysis of mode choice behavior of students in exclusive schools in metro Manila: The case of Ateneo de Manila University \& Miriam College. Proceedings of the Eastern Asia Society for Transportation Studies, 2005. 1116-1131.

DE LAPPARENT, M., AXHAUSEN, K. \& FREI, A. 2013. Long distance mode choice and distributions of values of travel time savings in three European countries. European Transport $\mid$ Trasporti Europei, 1-7.

EWING, R., SCHROEER, W. \& GREENE, W. 2004. School Location and Student Travel Analysis of Factors Affecting Mode Choice. Transportation Research Record, 1895, 55-63.

FUJII, S. \& GÄRLING, T. 2003. Application of attitude theory for improved predictive accuracy of stated preference methods in travel demand analysis. Transportation Research Part A: Policy and Practice, 37, 389-402.

GÄRLING, T. 2005. Changes of private car use in response to travel demand management. Traffic \& Transport Psychology, Theory and Application, ed. Underwood, Elsevier.

HATZOPOULOU, M. \& MILLER, E. J. 2009. Transport policy evaluation in metropolitan areas: The role of modelling in decision-making. Transportation Research Part A: policy and practice, 43, 323-338.

HENSHER, D. A. \& BRADLEY, M. 1993. Using stated response choice data to enrich revealed preference discrete choice models. Marketing Letters, 4, 139-151.

KHAN, O., FERREIRA, L. \& BUNKER, J. Modelling multimodal passenger choices with stated preference data. CONFERENCE OF AUSTRALIAN INSTITUTES OF TRANSPORT RESEARCH (CAITR), 26TH, 2004, MELBOURNE, VICTORIA, AUSTRALIA, 2004.

KHAN, O. A. 2007. Modelling passenger mode choice behaviour using computer aided stated preference data. Queensland University of Technology.

KLÖCKNER, C. A. \& FRIEDRICHSMEIER, T. 2011. A multi-level approach to travel mode choice - How person characteristics and situation specific aspects determine car use in a student sample. Transportation Research Part F: Traffic Psychology and Behaviour, 14, 261277.

KOCUR, G., ADLER, T., HYMAN, W. \& AUNET, B. 1981. Guide to forecasting travel demand with direct utility assessment.

KOPPELMAN, F. S. \& BHAT, C. 2006. A self instructing course in mode choice modeling: multinomial and nested logit models.

LINDHJEM, H. \& NAVRUD, S. 2011. Using internet in stated preference surveys: a review and comparison of survey modes. International Review of Environmental and Resource Economics (Forthcoming).

MARCUCCI, E. \& SCACCIA, L. 2004. Mode choice models with attribute cutoffs analysis: the case of freight transport in the Marche region. European Transport|Trasporti Europei, 21-32.

MEYER, M. D. \& MILLER, E. J. 1984. Urban transportation planning: a decision-oriented approach. 
MILLER, E. J., ROORDA, M. J. \& CARRASCO, J. A. 2005. A tour-based model of travel mode choice. Transportation, 32, 399-422.

MOHAMMED, A. \& SHAKIR, A. A. 2013. Factors that affect transport mode preference for graduate students in the national university of Malaysia by logit method. Journal of Engineering Science and Technology, 8, 351-363.

MÜLLER, S., TSCHARAKTSCHIEW, S. \& HAASE, K. 2008. Travel-to-school mode choice modelling and patterns of school choice in urban areas. Journal of Transport Geography, 16, 342-357.

NKURUNZIZA, A., ZUIDGEEST, M., BRUSSEL, M. \& VAN MAARSEVEEN, M. 2012. Modeling commuter preferences for the proposed bus rapid transit in Dar-es-Salaam. Journal of public transportation, 15, 5 .

NOMAN, S. M., AHMED, A. \& ALI, M. S. 2020. Comparative analysis of public transport modes available in Karachi, Pakistan. SN Applied Sciences, 2, 1-13.

PAS, E. I. Recent advances in activity-based travel demand modeling. Activity-Based Travel Forecasting ConferenceDepartment of TransportationFederal Transit AdministrationFederal Highway AdministrationOffice of the Secretary of TransportationEnvironmental Protection Agency, 1997.

POLYDOROPOULOU, A. \& BEN-AKIVA, M. 2001. Combined revealed and stated preference nested logit access and mode choice model for multiple mass transit technologies. Transportation Research Record, 1771, 38-45.

RAO, S. Sequential binary mode choice models for urban travel to work. Highway Research Bulletin, Indian Road Congress, Highway Research Board, 1993. 91-107.

RIZZI, L. I. \& DE DIOS ORTÚZAR, J. 2003. Stated preference in the valuation of interurban road safety. Accident Analysis \& Prevention, 35, 9-22.

RUDEL, R. 2004. Evaluation of quality attributes in the freight transport market. Stated preference experiments in Switzerland. European Transport $\mid$ Trasporti Europei, 52-60.

SHELDON, R. \& STEER, J. 1982. The use of conjoint analysis in transport research.

TASLIM, U., MUBASHSHIR, S., ARSHAD, SALAM, J., REHMAN, I. 2017. Karachi Traffic Chaos: Jamming the Wheels of Economy. Karachi, Pakistan. [Online]. Available: http://www.kcci.com.pk/research/wp-content/uploads/2017/09/Karachi-Traffic-ChaosJamming-the-Wheels-of-Economy.pdf [Accessed].

TUSHARA, T., RAJALAKSHMI, P. \& BINO, I. K. 2013. Mode Choice Modelling For Work Trips in Calicut City. International Journal of Innovative Technology and Exploring Engineering (IJITEE) ISSN, 2278-3075.

VOVSHA, P., PETERSEN, E. \& DONNELLY, R. 2002. Microsimulation in travel demand modeling: Lessons learned from the New York best practice model. Transportation Research Record, 1805, 68-77.

WEN, C.-H. \& KOPPELMAN, F. S. 2001. The generalized nested logit model. Transportation Research Part B: Methodological, 35, 627-641.

WHALEN, K. E., PÁEZ, A. \& CARRASCO, J. A. 2013. Mode choice of university students commuting to school and the role of active travel. Journal of Transport Geography, 31, 132142.

ZHANG, R., YAO, E. \& LIU, Z. 2017. School travel mode choice in Beijing, China. Journal of Transport Geography, 62, 98-110.

Acknowledgments

This research was carried with the support of Exascale Open Data Analytics Lab, National Center for Big Data and Cloud Computing (NCBC) and funded by the Higher Education Commission of Pakistan. Authors are thankful to the Department of Earthquake Engineering, NED University, and Prof. Rashid Ahmed Khan for granting permission to use their UAV for this research. 